\title{
The incidence of pneumonia in the paediatric population in Poland in light of the maps of health needs
}

\author{
Joanna Lange ${ }^{1}$ (D) $\cdot$ Jerzy Kozielski ${ }^{2} \cdot$ Kinga Bartolik $^{3} \cdot$ Paweł Kabicz $^{3} \cdot$ Tomasz Targowski $^{4}$
}

Received: 27 May 2020 / Accepted: 2 March 2021 / Published online: 17 April 2021

(C) The Author(s) 2021

\begin{abstract}
In Poland, no statistical data are available concerning the analysis of the incidence of pneumonia in inpatient children. The requirement for these data results mainly from the need to prepare systemic and economic solutions.

Aim This study aimed to use reported data for evaluating pneumonia incidence rates among hospitalised children and other parameters in various age groups.

Subject and methods A detailed analysis was performed as part of the Operational Programme Knowledge Education Development co-financed by the European Social Fund. Services reported to the National Health Fund in 2014 were considered, including pneumonia incidence among hospitalised children and mortality in specific age groups.

Results In 2014, a total of 68,543 children were hospitalised for pneumonia (68\% of all hospitalisations for acute respiratory diseases). Within each of the analysed age groups, boys were hospitalised more frequently. Irrespective of the place of residence, infants were most commonly hospitalised. It was observed that there was a significant difference between the incidence rate of pneumonia among hospitalised children in all analysed groups depending on the province. The average length of stay was 7.29 days, with infants requiring the longest stays ( 7.96 days), and $1.8 \%$ of children were rehospitalised within 30 days due to recurrence of pneumonia. The most commonly coded pathogens responsible for pneumonia included Mycoplasma pneumoniae, Streptococcus pneumoniae and Chlamydia spp. A total of 19 inpatient hospital deaths in the course of pneumonia were reported. Conclusions Based on our findings, it is warranted to utilize epidemiological knowledge for the planning of an appropriate level of service commissioned both in outpatient and inpatient facilities as well as for the estimation of institutional and staff needs necessary to secure these services.
\end{abstract}

Keywords Pneumonia incidence rate $\cdot$ Mortality $\cdot$ National Health Fund

Joanna Lange

iskry47@gmail.com

1 Department of Pediatric Pneumonology and Allergy, Medical University of Warsaw, Żwirki i Wigury 63A, 02-091 Warsaw, Poland

2 Department of Lung Diseases and Tuberculosis, Medical University of Silesia, Katowice, Poland

3 Department of Analysis and Strategy, Ministry of Health, Warsaw, Poland

4 Department of Geriatrics, National Institute of Geriatrics, Rheumatology and Rehabilitation, Warsaw, Poland

\section{Introduction}

Pneumonia in children is one of the most common reasons for encounters with paediatricians or family physicians both in the outpatient and inpatient settings. It is the cause of considerable morbidity and mortality, especially in children aged up to 5 years; however, the incidence of pneumonia and mortality is gradually decreasing (Troeger et al. 2017). According to the United Nations (UN) data, the incidence of pneumonia in highly developed countries is estimated at 1 per 66 children compared to 1 per 5 in low- and middle-income ones (Rudan et al. 2013). Epidemiological data in Eastern European countries, including Poland, regarding pneumonia in children remain scarce; however, several clinical and epidemiological studies have been published (Harat et al. 2013; Pawłowski and Stelmach 2017). The demand for epidemiological data on this disease entity in children results from the need for a 
well-thought-out implementation of systemic solutions that would - first of all —include the evaluation of health needs in this age group. Epidemiological knowledge is essential for the planning of an appropriate level of service commissioning both in outpatient and inpatient facilities as well as for the estimation of institutional and staff needs necessary to secure these services. Therefore, any epidemiological data from the countries in which hospital payment is based only on the National Fund may be helpful for other similar healthcare systems in Europe and other non-European countries.

The 'Maps of Health Needs: A Systemic and Implementation Analyses Base' co-financed by the European Social Fund as a part of the Operational Programme Knowledge Education Development, is a project that aims to implement activities and solutions in the Polish healthcare system (Ministry of Health 2016). Its purpose is to conduct discussions related to the aforementioned topic with the participation of National and Provincial Consultants both in paediatrics and respiratory medicine and to address decisions made by those who manage medical care in Poland at the national, regional and primary levels carried out by individual service providers.

The aim of this study was to analyse available data on pneumonia in children reported to the Polish National Health Fund (Narodowy Fundusz Zdrowia, NFZ) in order to evaluate epidemiological parameters, including incidence and mortality in children.

\section{Material and methods}

\section{Study population}

The study population comprised all children in Poland divided into three age categories (0-1-year-old, 2-5-year-old, and 617-year-old) in whom a hospitalisation was reported in 2014 due to the following diagnoses based on the International Classification of Diseases, 10th Revision (ICD-10): A37, B44, J10-J18 and J69.

\section{Data collection}

The data used in this study were derived from the Polish National Health Fund (Narodowy Fundusz Zdrowia - NFZ), which paid for all healthcare services in accordance with the principles of Diagnosis-Related Groups (DRG) based on the ICD-10 diagnosis.

The analysed database contained the following information:

- Children ID, including sex, age and address

- Type of ward providing hospitalisation

- Aetiological factors
- Accessibility to hospitals

- Reported ICD-9 code procedure

- Mortality rate within 90 days of discharge from hospital, including in-patient hospital deaths based on the available data from Ministry of Digital Affairs at the request of the Ministry of Health.

\section{Statistical analysis}

Statistical analysis was conducted using the R software, ver. 3.3.1, mainly based on the data.table package. The analyses used the data reported with the SWIAD reporting message from 1 January to 31 December 2014. Univariate analysis of variance test was used to differentiate the incidence rate of pneumonia between the province and the differences in each age group. Multifactorial analysis of variance test was used for a comparison of the percentage of death among children, depending on the province and age group.

The registered incidence rate in this study was defined as the number of new children hospitalised with a pneumonia reported within the publicly funded healthcare system per 100,000 children during the year. The rates were calculated taking into account the age of the children. A first-time patient was defined as a hospitalised child reported to the NFZ if they first appeared in the system with the diagnosis of pneumonia in 2014.

The analyses also considered:

- $\quad$ statistical data for the year 2014 provided by Statistics Poland, according to which boys predominated in every age group (Central Statistical Office 2015) three pathways through which children hospitalised with pneumonia appeared in the healthcare system: a hospital, specialist outpatient care (SOC) and an accident \& emergency department (A\&E)

- Number of hospitalisations by age and sex

- ALOS - average length of stay (in days)

- MLOS - median length of stay (in days)

\section{Results}

\section{General data}

In 2014 , a total of 68,543 children were hospitalised for pneumonia, accounting for $68 \%$ of the total number of hospitalisations for acute respiratory diseases. There were 1.07 hospitalisations per 1 patient. The number of hospitalisations in 395 hospitals all over Poland was 73,255, 58,379 of which ( $80 \%$ of all hospitalisations) were carried out 
in 194 hospitals (49\% of all hospitals), mainly in paediatric wards $(83.6 \%)$.

In the entire paediatric population up to 18 years of age, as many as $40.9 \%$ were infants, $40.9 \%$ were children aged 2 to 5 years, and $18.2 \%$ were children aged 6 years or older. Within each of the age groups analysed, boys were hospitalised more frequently, although the greatest percentage of boys was observed in the infant group. The average length of stay was 7.29 days with the longest stays among infants, namely 7.96 days. The mean age of the paediatric patient requiring hospitalisation for pneumonia was 3.25 years. The specific data on the percentage of all hospitalisations and the average and the median length of stay (ALOS and MLOS) by age are presented in Table 1.

The percentage share relative to the hospitalised paediatric population because of pneumonia was as follows - children up to 1 year of age constituted as much as $42.7 \%$, children 2 to 5 years of age $-38.7 \%$, and children above 6 years of age $18.6 \%$.

\section{The registered incidence of pneumonia among hospitalised children and distribution of pneumonia incidence in provinces in Poland}

Irrespective of the place of residence, children aged up to 1 year were hospitalised for pneumonia most frequently (3847.26 per 100,000). This parameter reached the value of 1572.72 per 100,000 in children aged 2 to 5 years and 270.59 per 100,000 in those aged 6 to 17 years. The lowest values in children aged 0 to 1 year and 6 to 17 years were recorded in the Zachodniopomorskie Province, and those in children aged 2 to 5 years were recorded in the Świętokrzyskie Province.

The distribution of pneumonia incidence among hospitalised children and the average length of stay (ALOS) in the provinces of Poland is illustrated in Fig. 1. The intensity of the colour of a province corresponds to the level of incidence per 100,000 children (with the lowest total value of 658 per 100,000 children being observed in the Zachodniopomorskie Province and the highest total value of 1625 per 100,000 children in the Łódź Province). The size of the circle corresponds to the absolute number of new cases in a province (with the maximum number of 8753 cases being observed in the Mazowieckie Province and the minimum number of 1465 cases in the Świętokrzyskie Province) and considers the three pathways of access to the healthcare system for each patient, i.e. SOC, hospitals and A\&E departments. The longest average length of stay (ALOS) in hospital was observed in the Podlaskie Province (7.97 days), and the shortest in the Pomorskie Province (6.30 days).

\section{Comparison of the incidence rate of pneumonia depending on the province}

It was observed, that there is a significant difference $(p<0.05)$ between the incidence rate of pneumonia among children depending on the province (Table 2). The highest values were observed in the Łódź, Podlaskie, Opolskie and KujawskoPomorskie Provinces. The lowest one, were found in the Zachodniopomorskie, Pomorskie, Świętokrzyskie and Śląskie Provinces (Fig. 2). Despite the fact that the most cases of pneumonia were registered in the Mazowieckie Province, the province, after the Ślaskie Province, achieved one of the lowest rates per 100,000 children. Moreover, ANOVA test results showed significant differences in analysed province for all age groups (Table 2).

\section{Rehospitalisations}

A total of 6089 rehospitalisations within 30 days of discharge were recorded, accounting for $8 \%$ of the baseline number of

Table 1 Detailed data on the percentages of all hospitalisations for pneumonia in the paediatric population by age and sex

\begin{tabular}{|c|c|c|c|c|c|c|c|c|}
\hline & $\begin{array}{l}\text { No. of } \\
\text { hospitalisations }\end{array}$ & $\begin{array}{l}\text { Percentage of } \\
\text { hospitalisations }\end{array}$ & $\begin{array}{l}\text { Number } \\
\text { of patients }\end{array}$ & $\begin{array}{l}\text { Percentage } \\
\text { of patients }\end{array}$ & $\begin{array}{l}\text { No. of hospitalisations } \\
\text { per patient }\end{array}$ & $\begin{array}{l}\text { Number of } \\
\text { patient- } \\
\text { days }\end{array}$ & ALOS & MLOS \\
\hline Total & 73,255 & 100 & 68,543 & 100 & 1.07 & 534,334 & 7.29 & 7 \\
\hline $0-1$ year & 30,208 & 41.24 & 28,006 & 40.86 & 1.08 & 240,340 & 7.96 & 7 \\
\hline $\mathrm{F}$ & 12,650 & 41.88 & 11,825 & 42.22 & 1.07 & 99,928 & 7.90 & 7 \\
\hline M & 17,558 & 58.12 & 16,181 & 57.78 & 1.09 & 140,412 & 8.00 & 7 \\
\hline $2-5$ years & 29,919 & 40.84 & 28,064 & 40.94 & 1.07 & 200,355 & 6.70 & 6 \\
\hline $\mathrm{F}$ & 13,482 & 45.06 & 12,689 & 45.21 & 1.06 & 91,200 & 6.76 & 7 \\
\hline M & 16,437 & 54.94 & 15,375 & 54.79 & 1.07 & 109,155 & 6.64 & 6 \\
\hline 6-17 years & 13,128 & 17.92 & 12,473 & 18.20 & 1.05 & 93,639 & 7.13 & 7 \\
\hline $\mathrm{F}$ & 6179 & 47.07 & 5866 & 47.03 & 1.05 & 44,616 & 7.22 & 7 \\
\hline M & 6949 & 52.93 & 6607 & 52.97 & 1.05 & 49,023 & 7.05 & 7 \\
\hline
\end{tabular}

F, female; M, male; ALOS, average length of stay in days; MLOS, median length of stay in days 
Fig. 1 Registered incidence of pneumonia among hospitalised children and the average length of stay (ALOS) in hospital in the provinces of Poland

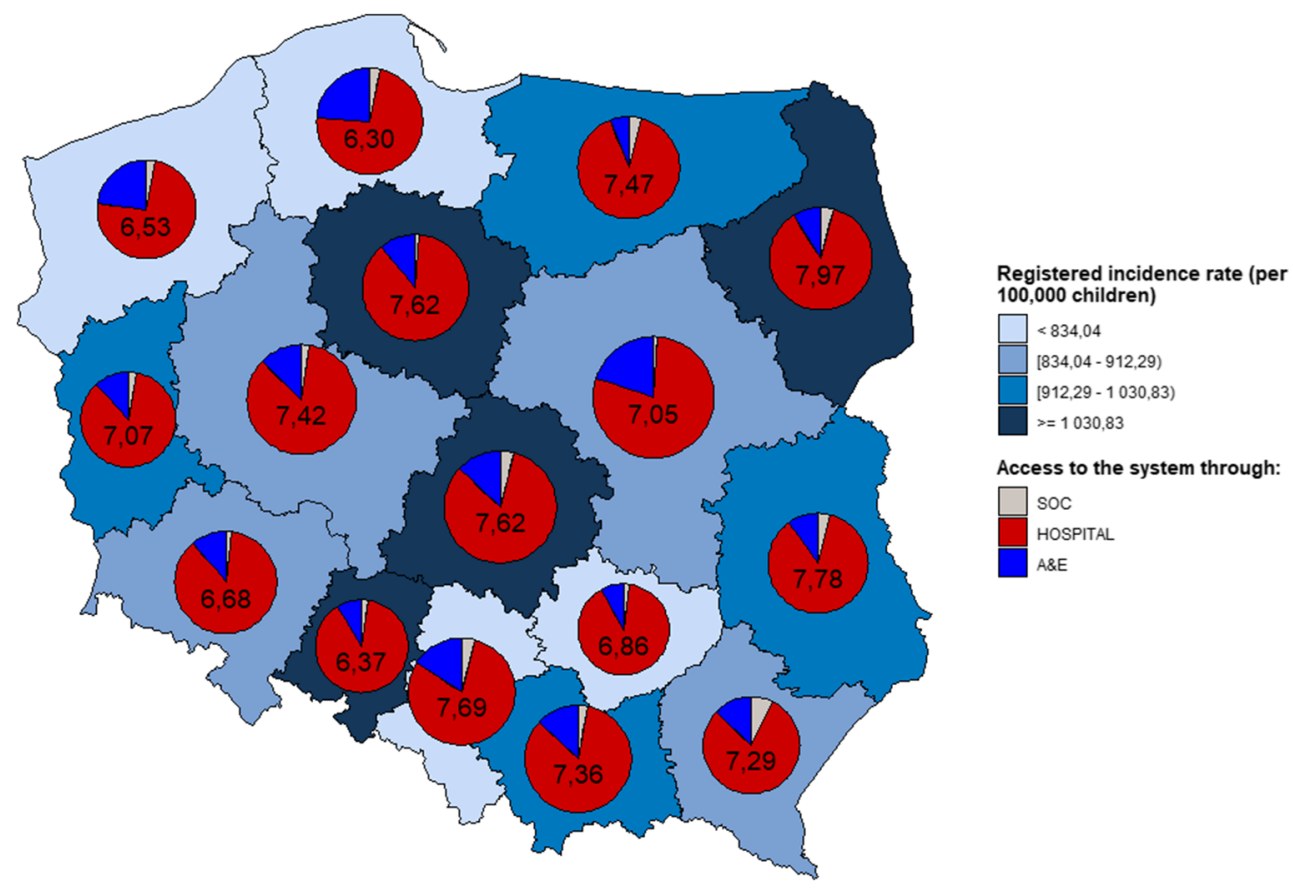

hospitalisations. Of these, 1340 rehospitalisations $(22 \%$ of $6089 ; 1.8 \%$ of the total number of hospitalisations) were associated with another diagnosis of pneumonia.

\section{Seasonality of pneumonia cases}

A pronounced seasonality of cases and hospitalisations for pneumonia was observed, with the nadir in the summer months (from June to August) and an increased incidence in the period of autumn and winter. Hospitalisations for pneumonia in 2014 peaked in the middle of March (early spring). The second wave was observed in November and December, with a characteristic decline over the Christmas period (Fig. 2).

\section{Aetiological factors of pneumonia in children}

In the case of 44,794 hospitalisations $(61 \%)$, codes for pneumonia caused by an unidentified aetiologic factor were assigned. An ICD-10 code for bacterial pneumonia was assigned in 16,454 cases $(22.5 \%)$ and a code for viral pneumonia in 10,186 cases (13.9\%). In 689 cases, Bordetella pertussis infection as a cause of pneumonia was the reason for hospitalisation. A diagnosis of pneumonia caused by the influenza virus was made in 570 cases of hospitalisation, aspiration pneumonia in 543 and fungal infection in 19 cases. In the group of 16,454 hospitalisations coded as bacterial pneumonia, a detailed pathogen was attributed in only $23 \%$ of the hospitalisations. The most commonly coded pathogens were Mycoplasma pneumoniae, Streptococcus pneumoniae and Chlamydia spp. in 2398, 304 and 212 hospitalisations, respectively. Code for the unspecified bacterium was pointed out in 13,126 hospitalisations. Other reported pathogens ( $<100$ separately) included Staphylococcus spp., Escherichia coli, Haemophilus influenzae, Klebsiella pneumoniae, Pseudomonas spp., other oxygen-depended Gram (-) bacteria and Streptococcus group B.
Table 2 Results of one-way ANOVA for the incidence rate of pneumonia among hospitalised children by province for age groups (in total and in subgroups)

\begin{tabular}{lllllll}
\hline Age group & Source of variation & df & Sums of squares & Mean square & F statistic & P \\
\hline $0-17$ & Province & 15 & $37,966,899$ & $2,531,127$ & 7.181 & $<0.0001$ \\
& Residuals & 364 & $128,299,702$ & 352,472 & & \\
$0-1$ & Province & 15 & $704,234,797$ & $46,948,986$ & 4.0963 & $<0.0001$ \\
& Residuals & 356 & $4,080,267,843$ & $11,461,427$ & & \\
$2-5$ & Province & 15 & $120,202,670$ & $8,013,511$ & 9.1899 & $<0.0001$ \\
& Residuals & 356 & $310,428,856$ & 871,991 & & \\
$6-17$ & Province & 15 & $2,890,558$ & 192,704 & 4.8644 & $<0.0001$ \\
& Residuals & 356 & $14,103,043$ & 39,615 & & \\
\hline
\end{tabular}




\section{Accessibility to hospitals in Poland}

The analysis also included the accessibility to hospitals to children diagnosed with pneumonia. When analysing areas within a 20,30 , and $40 \mathrm{~km}$ radius of a public healthcare facility, some of the provinces of Poland were not covered in full. Even in the radius $40 \mathrm{~km}$, three region still had poor accessibility to the nearest hospital: Gryfice county in the Zachodniopomorskie Voivodeship, Słubice county in the Lubuskie Voivodeship and Bieszczady county in the Podkarpackie Voivodeship. Only when a radius of $50 \mathrm{~km}$ was set did the coverage include all of Poland.

\section{ICD-9 medical procedures reported in children hospitalised for pneumonia}

In accordance with the International Classification System for Surgical, Diagnostic and Therapeutic Procedures (ICD-9, version 5.36), the ten procedures most commonly reported in children hospitalised for pneumonia were analysed. ${ }^{1}$ Among these, the 'diagnostic interview and evaluation' procedure was most commonly reported (in $96 \%$ of the cases). Obtaining a plain chest radiograph was recorded in $57,174(78 \%)$ hospitalisations. Antibiotic administration was recorded in 3/ 4 of the patients, while administration of oxygen using various methods was only recorded in $53 \%$ of the cases. Intravenous rehydration was recorded in $43 \%$ of the hospitalisations but establishing vascular access in order to administer medication was only recorded in $35 \%$. Urinalysis was coded in every fourth child, while blood counts and C-reactive protein levels were reported in $22 \%$ and $21 \%$ of the hospitalised patients, respectively. Steroid injection was reported as a treatment intervention in as many as $17 \%$ of the cases.

\section{Mortality for pneumonia}

A total of 117 deaths among children were reported in 2014 within 90 days of discharge from hospital. The total number of in-patient hospital deaths was 19, including five deaths in infants up to 1 year of age, four deaths in children aged 2 to 5 years, and ten in children aged 6 years or older. Cardiac and/ or respiratory arrest and respiratory failure were reported as the principal cause of death. The diagnosis coded J96 (respiratory failure) was established independently as the cause of death in 46 children. In some of the children with pneumonia reported as the cause of death, comorbid ICD-10 codes were provided, which made it possible to identify underlying conditions such as cerebral palsy, genetic syndromes, blood neoplasms or metabolic diseases. Based on the multifactorial analysis of variance test in the pneumonia group, death was

\footnotetext{
${ }^{1}$ In 2014, the procedures that were completed were entered into the system manually.
}

statistically often observed in the group of children between 0 to 1 year; however, there were no differences depending on the treatment in the analysed province (Table 3).

\section{Discussion}

In Poland in 2014, 68,538 children were hospitalised for pneumonia, corresponding to 930 cases per 100,000. According to the available data published by Statistics Poland, the paediatric population aged up to 18 years was 7,367,100 at that time (Central Statistical Office 2015), which allows estimating the registered incidence among hospitalised children as 1 per 108 children. This value is higher than that observed in other countries with high per capita income even though it is notably much lower than that observed in low- to intermediateincome countries. For comparison, a total of 124,900 hospitalisations for pneumonia were recorded in the US in 2012. According to demographic data, the number of children in the US at that time was 73.7 million, which makes it possible to calculate the incidence rate at 1 per 600 , assuming a negligible percentage of children requiring rehospitalisation. This considerable difference between the data may, for example, be due to the compliance with hospitalisation eligibility criteria. In Poland, it is often the case that children who could successfully be treated in the outpatient setting are admitted to hospital. This situation may also be due to the accessibility to general practitioners (GPs), including paediatricians, whose number is decreasing yearly from a total of 12,531 in 2014 to 10,569 in 2017 (Information System Center Health Protection 2018). The increasing staffing problems and the increasing age of practising doctors ( $>70 \%$ of whom are over 50 years of age) may translate into restricted access to outpatient care and therefore faster referral of the young children to the hospital, even with mild pneumonia.

A separate analysis was conducted for the group of children up to 5 years of age. According to our data, they accounted for $81.8 \%$ ( 56,070 children) of the hospitalised population, which enables the incidence rate to be calculated at 0.02 per 1 child per year. This is consistent with the data from other developed countries (European Lung White Book n.d.-a, Chap. 16). It is noteworthy that half of the population of small children required hospitalisation in their first year of life. Furthermore, children aged up to 5 years were hospitalised five times more frequently than older children and adolescents $(81.8 \%$ vs $18.2 \%)$. In each age group, hospitalisations of boys predominated, which is consistent with the predominance of boys in the population of children aged up to 17 years (Central Statistical Office 2015). Jain et al. estimated the annual pneumonia hospitalisation in the US in children under 2 years of age at 62.2 per 10,000 (Jain et al. 2015). Tong et al. found that the annual frequency of pneumonia was also highest in the group of children under 2 years. This trend was also observed 
Fig. 2 Daily number of hospitalisations for pneumonia in children, in Poland, in 2014

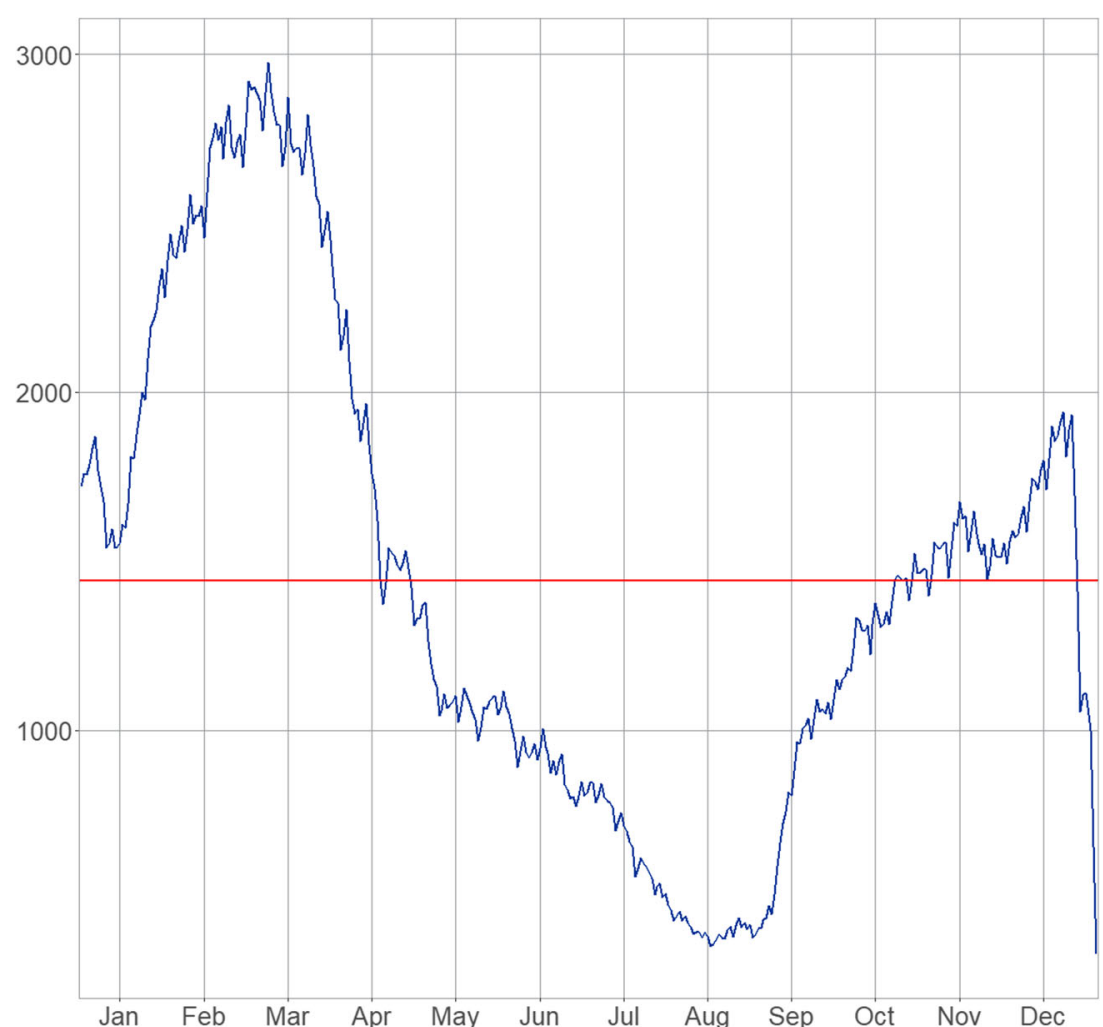

after pneumococcal vaccine introduction (Tong et al. 2018). Nguyen et al. also observed a considerably high percentage of children aged up to 4 years in the population of Vietnamese children hospitalised in three hospitals. Depending on the hospital category, the percentage within this age group ranged from $78.6 \%$ to $91.2 \%$. The youngest children, aged up to 2 years, contributed to the percentage considerably. They required hospitalisation nearly three times more often than the group aged 2 to 4 years, and seven times more frequently than children aged 6 to 14 years. The percentage of hospitalisations in the entire population of Vietnamese children among boys was higher than that in Poland (63.8\% vs 55.9\%) (Nguyen et al. 2017). In a South Korean study, $44.9 \%$ of all the pneumonia patients were children younger than 10 years (Health Insurance Review \& Assessment Service 2014). In the study by Lee et al. the hospital admission rate was $43.5 \%$. The highest percentage was observed in the subgroup aged 1 to 3 years (Lee et al. 2016). In the multicentre Etiology of Pneumonia in the Community (EPIC) study, children aged up to 4 years accounted for nearly $70 \%$ (Jain et al. 2015).
The analysis in our study also included the average length of stay (ALOS) in days for pneumonia, which equalled 7.29 days in 2014, which was shorter than LOS from an earlier Polish study-10.1 days vs. 8.2 in 2007 and 2011, respectively (Gajewska et al. 2016). In our study, infants were hospitalised for the longest time (7.96 days); however, in Gajewska et al.'s study, it was nearly 11 days and 9 days in 2007 and 2011, respectively (Gajewska et al. 2016). Shortening the hospitalisation time in our study due to pneumonia confirms the nationwide trend observed for several years; however, it is still is too long. For comparison, in the US, the average length of stay irrespective of the reason for hospitalisation was 3.9 days in 2012. The shorter lengths of stay there were likely due to the insurance system in the USA, which is based on private insurance in as many as $43.6 \%$ of the cases, and a different settlement system for state insurance than that in Poland, which is mainly based off of the National Fund payment (Witt et al. 2014).

In our study, we also compared the incidence of pneumonia with the dependency on the analysed province. We found, that
Table 3 Results of multifactorial ANOVA for the percentage of deaths among the children with pneumonia by province and age group

\begin{tabular}{llllll}
\hline Source of variation & df & Sums of squares & Mean square & F statistic & P \\
\hline Province & 15 & 0.00157 & 0.0001044 & 1.100 & 0.35160 \\
Age group & 2 & 0.00127 & 0.0006362 & 6.700 & 0.00128 \\
Province*Age group & 30 & 0.00215 & 0.0000717 & 0.755 & 0.82751 \\
Residuals & 1114 & 0.10508 & 0.0000943 & & \\
\hline
\end{tabular}


there is a significant difference $(p<0.05)$ between the incidence rate of pneumonia among children depending on the province. Based on the available data, it is difficult to clearly explain the observed differences between them. They can result from many aspects, e.g. reporting (increase in the number of cases), coexistence of risk factors or availability to hospital and other treatment regimens.

We also analysed the number of rehospitalisations within 30 days of discharge from the hospital. In 2014, $8 \%$ of rehospitalisations in the paediatric population were reported irrespective of the reason, while $1.8 \%$ of the total number of hospitalisations were subsequent stays for pneumonia. Our data were similar to the retrospective evaluation of a cohort of children hospitalised during a period of 4 years in 43 hospitals in the US for pneumonia. Neuman et al. observed 7.7\% all-cause rehospitalisations and $3.1 \%$ rehospitalisations for pneumonia (Neuman et al. 2014).

Based on the analysis of the available data, a pronounced seasonality of cases and hospitalisations for pneumonia could be observed, with the nadir in the summer months (from June to August) and an increased incidence in the period of autumn and winter. In Tong et al.'s study, seasonality of pneumonia was consistent during 2008-2014, with a peak in the winter months (Tong et al. 2018). In a Korean study, presentation rates were highest in April, followed by January, March and May. In the summer months (June through August), authors observed the lowest number of Emergency department visits due to pneumonia (Lee et al. 2016). In our study, hospitalisations for pneumonia in 2014 peaked in the middle of March, which temporarily coincided with the influenza epidemic in Poland (National Institute of Public Health n.d.). This may be explained, for instance, by the synergy between an infection with the influenza virus and abacterial infection, e.g. with Streptococcus pneumoniae. The analysis of pneumonia diagnoses according to the aetiological factor points to a very high number of pneumonias coded as pneumonia of unspecified aetiology or bacterial pneumonia caused by unspecified bacteria. Our data are similar to a cited Korean study in which undetermined origin was the most frequent diagnosis 59.3\% (Lee et al. 2016). Our data could be explained by the widespread use of empirical antibiotic therapy and the lack of diligence in reporting microbiological tests. This may also refer to the poor status of the microbiological evaluation of pneumonia in some hospitals. Moreover, the payer does not require a bacteriological test or other microbiological studies be reported in cases of the diagnosis of pneumonia.

It is worth bearing in mind that there was a considerable percentage of coded atypical infections in the paediatric population, in which - with the exception of the infantile period-Streptococcus pneumoniae is the most common pathogen causing community-acquired pneumonia. The highest percentage of children with mycoplasmal pneumonia (57.7\%) was observed by Lee et al. (2016). The low percentage of pathogens typical of community-acquired pneumonia among the hospitalised patients in our study may be due to the reasons mentioned above. Furthermore, it cannot be excluded that many pneumonia cases are managed in the outpatient setting, as evidenced by a relatively low hospitalisation rate for pneumonia in the Polish population aged over 15 years compared to the other European countries, e.g. according to the 2012 data by the WHO, Eurostat, and the World Bank: 150.4 per 100,000 in Poland, 516.0 per 100,000 in Finland, 246 per 100,000 in Hungary, 200.3 per 100,000 in Germany, 186.7 per 100,000 in France and 176.2 per 100,000 in the Czech Republic (European Lung White Book n.d.-b, Chap. 18). Furthermore, the reduction in the incidence of pneumococcal pneumonia following the introduction of a vaccine is of note. A published analysis of the incidence of pneumonia after the 2006 introduction of a 7-valent pneumococcal vaccine in Kielce, Poland, showed a nearly $65 \%$ reduction in the incidence based on this aetiology (Patrzałek et al. 2010). Similar findings were published in Australia and in the USA (Jardine et al. 2010; Simonsen et al. 2011; Tong et al. 2018).

Our analysis also included the accessibility to hospitals in cases where children diagnosed with pneumonia required hospitalisation. The use of a radius of $50 \mathrm{~km}$ of the nearest hospital provided coverage with inpatient facilities to all children. The question is, if $50 \mathrm{~km}$ to the nearest hospital is close or rather too far? In cases of uncomplicated pneumonia, it is important to secure a bed in a hospital that is closest to the child's place of residence. Children with pneumonia complications require transport to specialist centres. For instance, a trend of sending paediatric patients to specialist centres is observed in the USA. According to the recently published data from four most populated states, the number of children requiring hospitalisation decreased, while transfer to higher reference centres increased (24.6\%); however, the highest percentage of children transferred to other hospitals was observed in patients with abdominal pain and patients with asthma (França and McManus 2018).

As part of the project, the ten most commonly reported procedures performed during hospitalisations were identified based on the International Classification System for Surgical, Diagnostic and Therapeutic Procedures: ICD-9, Polish version 5.36 (ICD-9-PL). In 78\% of the cases, a radiological study was reported, while ultrasonography, a procedure that is highly significant due to radiological safety, was not among the most commonly performed procedures. Interestingly, in $17 \%$ of the cases, steroid use in children with pneumonia was reported even though these drugs were not included in the guidelines on the treatment of pneumonia in 2014.

The in-hospital morbidity of $0.03 \%$ in our study $(n=19)$ is similar to that in the Korean report (Lee et al. 2016); however, a significant difference was observed between our data and the data published by the National Tuberculosis and Lung Disease Research Institute on the mortality for pneumonia. (National Tuberculosis and Lung Disease Research Institute 2015). 
Moreover, from the Eurostat data, a total of 108 children aged up to 15 years and 19 children aged 15 to 19 years died for pneumonia or its complications (Eurostat n.d.). This discrepancy may, among other reasons, be due to the inability to complete death certificates correctly. Circulatory or respiratory arrest as a manifestation of acute respiratory failure, which is commonly indicated as the cause of death in death certificates, is not a cause of death but a consequence of a primary cause. The J96 code (respiratory failure) as the cause of death in 46 children and as a comorbid condition for pneumonia in nine children is among the so-called 'garbage codes'. According to the WHO, garbage codes are those ICD-10 codes that correspond to imprecise and inaccurate descriptions of conditions and diseases, which makes a precise definition of the cause of death impossible. Our findings may be universal, especially for other communities with similar health care systems. Firstly, comparing with other available data from European and non-European countries presented in the discussion highlights their value. Secondly, the use of the universal ICD-10 codes provided an unselected sample of hospital episodes. This made it possible to use data from the National Health Fund for international comparisons, where ICD-10 codes are used. Moreover, it makes the National Health Fund an important source of data for the health economy. Thirdly, the epidemiological data presented in the article can also be used by international organisations and institutions in their own studies. For instance, the Global Burden of Disease (GBD) study, the most comprehensive worldwide observational epidemiological study to date, collects data from all over the world and provides a tool to quantify health loss from hundreds of diseases, injuries and risk factors so that health systems can be improved and disparities can be eliminated.

Our study has some limitations. The most important includes the fact that aetiological factors were based on the ICD-10 codes. Some of them, as authors believe, were secondary to bacteriological findings during hospitalisation, but more probably they were related to the DRGs and secondary to the highest reimbursement of patient's treatment costs.

Our analysis raises several questions for future investigations. Firstly, why are there still so many hospitalisations due to respiratory diseases? Secondly, what is the importance of the distance of residence to hospitals, insurance and LOS in the hospital? Thirdly, how to shorten the LOS, increase the efficiency of the hospital system and reduce costs without jeopardising the quality of care. Understanding these factors will provide the information needed to plan and implement evidence-based prevention and treatment strategies.

\section{Conclusion}

In summary, the data presented by the authors of the present paper are quite consistent with those available in the literature. Differences are mostly identified for the aetiological factors of pneumonia in the population of children requiring hospitalisation. The use of automated data entry from medical IT systems and the revision of the pricing of hospitalisations by the payer depending on the patient's condition and the actual diagnostic and therapeutic costs may considerably improve the analysed data.

\section{Significance for public health}

Pneumonia in children is one of the most common reasons for encounters with paediatricians or family physicians both in the outpatient and inpatient settings. Epidemiological data in many European countries, also in Poland, regarding pneumonia in children remain scarce. The demand for nationwide epidemiological data on this disease in children results from the need for a well-thought-out implementation of systemic solutions that would - first of all-include the evaluation of health needs in this age group. Epidemiological knowledge is essential for the planning of an appropriate level of service commissioned both in outpatient and inpatient facilities as well as for the estimation of institutional and staff needs necessary to secure these services. Analysis of the available data with the evaluation of epidemiological parameters are important for Health Founders worldwide.

Authors' contributions LJ - conception and design of the study, manuscript draft preparation, data analysis, literature search.

$\mathrm{KJ}$ - data analysis, literature search, critical revision of final version with approval.

BK - data acquisition, analysis and interpretation of data, final approval of the version to be published.

$\mathrm{KP}$ - data acquisition, analysis and interpretation of data, final approval of the version to be published.

TT - interpretation of data, literature search, critical and final approval of the version to be published.

Funding The article was prepared as part of the project titled: 'Maps of Health Needs: A Systemic and Implementation Analyses Base' (number POWR.05.02.00-00-0149 /15-01) co-financed by the European Union from the European Social Fund as part of the Operational Programme Knowledge Education Development.

\section{Declarations}

Ethical statement The manuscript has not been submitted to more than one journal for simultaneous consideration. The manuscript has not been published previously partly or in full. A single study is not split up into several parts to increase the quantity of submissions. No data have been fabricated or manipulated to support our conclusions. Authors whose names appear on the submission have contributed sufficiently to the scientific work and therefore share collective responsibility and accountability for the results.

All authors have read the final draft of the manuscript. The authors of this paper have complied with all ethical standards. The funding source played no role in the design of the study, the analysis and interpretation of data, and the writing of the paper. 
Conflict of interest The authors declare that they have no conflict of interest.

Open Access This article is licensed under a Creative Commons Attribution 4.0 International License, which permits use, sharing, adaptation, distribution and reproduction in any medium or format, as long as you give appropriate credit to the original author(s) and the source, provide a link to the Creative Commons licence, and indicate if changes were made. The images or other third party material in this article are included in the article's Creative Commons licence, unless indicated otherwise in a credit line to the material. If material is not included in the article's Creative Commons licence and your intended use is not permitted by statutory regulation or exceeds the permitted use, you will need to obtain permission directly from the copyright holder. To view a copy of this licence, visit http://creativecommons.org/licenses/by/4.0/.

\section{References}

Central Statistical Office (2015) Demographic yearbook of Poland Warsaw. https://stat.gov.pl/obszary-tematyczne/rocznikistatystyczne/roczniki-statystyczne/rocznik-demograficzny2015,3,9.html

European Lung White Book Chapter 16 (n.d.-a) Paediatric Respiratory Diseases. https://www.erswhitebook.org/chapters/paediatricrespiratory-diseases/

European lung white book. Chapter 18 (n.d.-b) Acute lower respiratory infections. https://www.erswhitebook.org/files/public/Chapters/18 ALRIs.pdf

Eurostat (n.d.) http://ec.europa.eu/eurostat/web/products-datasets/-/hlth cd_aro

França UL, McManus ML (2018) Trends in regionalization of hospital care for common pediatric conditions. Pediatrics 141(1):e20171940. https://doi.org/10.1542/peds.2017-1940

Gajewska M, Lewtak K, Scheres J, Albrecht P, Goryński P (2016) Trends in hospitalization of children with bacterial pneumonia in Poland. Central Eur J Public Health 24(3):188-192. https://doi.org/10. 21101/cejph.a4164

Harat R, Gorny G, Jorgensen L, Pluta J, Gray S, Dartois N, Ye J, Gutterman EM (2013) A retrospective study of hospitalized pneumonia in two polish counties (2006-2008). Pneumonol Alergol Pol 81(5):429-438

Health Insurance Review \& Assessment Service (2014) Press release November 21, vol 2014. Health Insurance Review \& Assessment Service, Seoul

Information System Center Health Protection (2018) https://www.csioz. gov.pl/fileadmin/user_upload/Biuletyny_informacyjny/biuletyn_ 2018 5c3deab703e35.pdf

Jain S, Williams DJ, Arnold SR, Ampofo K, Bramley AM, Reed C, Stockmann $\mathrm{C}$ et al (2015) Community-acquired pneumonia requiring hospitalization among US children. NEJM 372:835-845

Jardine A, Menzies RI, McIntyre PB (2010) Reduction in hospitalizations for pneumonia associated with the introduction of a pneumococcal conjugate vaccination schedule without a booster dose in Australia. Pediatric Infect Dis J 29(7):607-612. https://doi.org/10.1091/inf. 0b013e3181d7d09c
Lee CH, Won YK, Roh E-J, Suh DI, Chung EH (2016) A nationawide study of children and adolescents with pneumonia who visited emergency Department in South Korea in 2012. Korean J Pediatrics 59(3):132-138. https://doi.org/10.3345/kjp.2016.59.3.132

Ministry of Health (2016) http://www.mpz.mz.gov.pl/mapy-dla-30-grupchorob

National Institute of Public Health (n.d.)- National Institute of Hygiene. http://wwwold.pzh.gov.pl/oldpage/epimeld/grypa/index.htm

National Tuberculosis and Lung Disease Research Institute (2015) Mortality from pneumonia by sex and age groups. Bulletin

Neuman MI, Hall M, Gay JC, Blaschke AJ, Williams DJ, Prikh K, Hersh AL et al (2014) Readmission among children previously hospitalized with pneumonia. Pediatrics 134:100-109. https://doi.org/10. 1542/peds.2014-0331

Nguyen TKP, Nguyen DV, Truong TNH, Tran MD, Graham SM, Marais BJ (2017) Disease spectrum and management of children admitted with acute respiratory infection in Viet Nam. Tropical Med Natl Health 11(6):688-695. https://doi.org/10.1111/tmi.12874

Patrzałek M, Albrecht P, Sobczyński M (2010) Significant decline in pneumonia admission rate after the introduction of routine $2+1$ dose schedule heptavalent pneumococcal conjugate vaccine (PCV7) in children under 5 years of age in Kielce, Poland. European J Clin Microbiol Infectious Diseases 29(7):787-792. https://doi.org/10.1007/s10096-010-0928-9

Pawłowski M, Stelmach I (2017) Clinical picture and epidemiology of atypical and pertussis-related pneumonia in unsuccessfully treated paediatric outpatients, hospitalised during the infectious season of 2015-2016. Pediatria i Medycyna Rodzinna 13(1):103-107. https:// doi.org/10.15557/PiMR.2017.0010

Rudan I, O'Brien KL, Nair H, Lu L, TheodoratouE, Qazi S, Lukšić CL, Walker F, Black RE, Campbell $\mathrm{H}$ on behalf of Child Health Epidemiology Reference Group (CHERG) (2013) Epidemiology and etiology of childhood pneumonia in 2010: estimates of incidence, severe morbidity, mortality, underlying risk factors and causative pathogens for 192 countries. Glob Health 3:10401. https://doi.org/10.7189/jogh.03.010401

Simonsen L, Taylor RJ, Young-Xu Y, Haber M, May L, Klugman KP (2011) Impact of pneumococcal conjugate vaccination of infants on pneumonia and influenza hospitalization and mortality in all ages groups in the united state. MBio 2(1):e00309-e00310. https://doi. org/10.1128/mBio.00309-10

Tong S, Amand C, Kieffer A, Kyaw MH (2018) Trend in healthcare utilization and costs associated with pneumonia in the United States during 2008-2014. BMC Health Services Res 18:715. https://doi.org/10.1186/s12913-018-3529-4

Troeger C, Forouzanfar M, Rao PC et al (2017) Estimates of the global, regional, and national morbidity, mortality, and aetiologies of lower respiratory tract infections in 195 countries: a systematic analysis for the global burden of disease study 2015. Lancet Infectious Disease 17:1133-1161. https://doi.org/10.1016/S1473-3099(17)30396-1

Witt WP, Weiss AJ, Elixhauser, A (2014) Overview of Hospital Stays for Children in the United States. HCUP Statistical Brief \#187. December 2014. Agency for Healthcare Research and Quality, Rockville, MD. http://www.hcup-us.ahrq.gov/reports/statbriefs/ sb187-Hospital-Stays-Children-2012.pdf

Publisher's note Springer Nature remains neutral with regard to jurisdictional claims in published maps and institutional affiliations. 